\title{
LUIS ENRIQUE ALONSO (2009), Prácticas económicas y economía de las prácticas. Crítica del postmodernismo liberal. Madrid, Los libros de la Catarata, $262 \mathrm{pp}$.
}

Con La era del consumo, Luis Enrique Alonso marca un hito en la sociología española: una especie de rubicón por el que queda institucionalizada definitivamente la sociología del consumo en nuestro país, sin posibilidad de vuelta atrás. Para quienes se incrustan en ese campo de la investigación social, es una obra de referencia obligada, por todo lo que pone de manifiesto, por todas las vías que abre a la sociología del consumo. Por eso, había expectación sobre los siguientes pasos del autor en la materia, que, por otro lado, no es la única que domina. Es más, el gran atractivo de su escritura consiste en la enorme capacidad para integrar, junto a distintas especies y subespecies del interés sociológico, saberes económicos, filosóficos, lingüísticos y, sobre todo, las reflexiones universales de mayor actualidad. Una expectación que, además, se alimenta de la prolífica condición del autor.

En Prácticas economías y economía de las prácticas, vuelve a parte de las herramientas conceptuales expuestas en su sociología del consumo; pero lo hace para ir más allá de ésta, poniendo un especial foco inicial en las organizaciones. Un campo en el que lleva realizando investigaciones empíricas e los últimos años, importante parte de ellas con la buena colaboración de Carlos Fernández. Es en el prefacio dedicado a las organizaciones donde nos hace una propuesta de estudio sociohistórico de las mismas que va más allá de las mismas.

La sociología del consumo y de las organizaciones se insertan en un gran engranaje teórico y políticamente crítico de más altura, bajo el concepto de economía de las prácticas. Un concepto que arraiga en la obra de Pierre Bourdieu y que se enfrenta a la dominante actuación de una disciplina llamada economía. Para ser un poco más precisas, a la actuación de una economía abstracta en lo formal y normativamente excluyente en sus efectos políticos. Frente a la generalización abstracta y formalista de la economía, en la que la disciplina fundamenta una racionalidad propia de sujetos asimismo un tanto abstractos (organización, comportamiento de consumo), por su increíble autonomía, el enfoque sociopragmático de Alonso los sujeto al sujeto del contexto social (sistema político, sistema ideológico y el propio sistema económico, como campo en el que luchan distintos actores), en el que se encuentran los sujetos concretos: organizaciones concretas, consumidores concretos.

El texto es una especie de autobricolage, pues articula retazos ya leídos en el autor. Si bien es cierto que ningún capítulo ha sido enteramente publicado, si son muchos los ecos de textos anteriores en varios de ellos. Tal vez lo más nuevo es el aludido cemento teórico que los une, constituyéndolos en vértebras de una sólida columna vertebral teórica.

Tras el prefacio, el texto entra de lleno en un bloque en lo que creo más le gusta hacer al autor, como es dialogar con las obras de gran relevancia sociológica. El primer capítulo de sus bases teóricas sintomáticamente lo dedica a Halbwachs $-\mathrm{y}$ sus sucesores- y la memoria colectiva. Una memoria que ontológicamente es precedente a la memoria individual. Así, nos sitúa en lo que puede entenderse como la protohistoria de la sociología del consumo: Halbwachs, Goblot, de quien Alonso se ha encargado de defender su 
estratégico papel entre nosotros, y Chombart de Lawe, pertinentemente reivindicado. Entre estos autores se acuña una sociología del consumo que sospecha del concepto de necesidades cuando se aplica fuera de su matriz social, que discute sobre cuál es la unidad de consumo, pues ceñirlo al individuo es quedarse en un punto ciego. Y casi al final de esta serie llega Baudrillard, con sus luces y sus sombras. Pese a la exigencia de síntesis, las criticas a este autor son acertadas. Sólo una mínima disidencia sobre su evolución, ya que se dice que camina hacia un enorme culto al objeto (pág. 62), cuando creo que hacia donde camina es hacia el culto de la comunicación (La guerra del Golfo no ha tenido lugar, El crimen perfecto, El paroxista indiferente, Pantalla total). Es más, podría decirse que el objeto de consumo queda reducido a mero significante en la obra de Baudrillard.

La senda francesa de la sociología del consumo adquiere su cima con Bourdieu y La distinción. Con ella, tenemos principalmente: la vinculación a la producción, a través del concepto de habitus; la fijación de las necesidades en la estructura social; y la exigencia de una sociología económica total. Un encuentro con el autor francés, para el que se realiza una exposición de la figura intelectual. Nos introduce en su biografía y su bibliografía -como ya nos adelantara inicialmente en el texto que dedicó al autor, con motivo de su reciente fallecimiento, en la Revista Española de Investigaciones Sociológicas- para sumergirnos en el concepto de práctica.

El dúo Wright Mills/Moya, para ser más exacto, el primero de la mano del segundo, pone el tornillo analítico nuevamente del lado de las organizaciones: las corporaciones y los «señores de las corporaciones» (pág. 109), las elites y, lo que es más importante, el lugar privilegiado de la corporación en la estructura- ción del capitalismo. En un texto que en su versión pública inicial sirvió de homenaje al sociólogo español, éste aparece como continuador del programa sociológico del norteamericano y como líder de su aplicación en España, a las elites del capitalismo español. Se encuentra con el sujeto de nuestro desarrollo económico de la segunda mitad del siglo pasado.

En el cuarto capítulo se realiza el salto desde la teoría a distintos análisis empíricos del consumo. Siempre situándolos históricamente y con referencia al fordismo. Es decir, se compara la situación actual con los años del desarrollo welfarista y de la ciudadanía laboral. Frente a ello, un presente caracterizado por la precariedad labroal, la fragmentación, el individualismo y la distancia entre la ciudadanía y el empleo, aun cuando tras ella se estuviese ante la expansión de una sociedad particularmente disciplinaria (pág. 134). Capitalismo y formas de control quedan hermanadas y frente a frente. Impecable síntesis del desarrollo del capitalismo en el último medio siglo, con especial atención a los conflictos de intereses.

Lo que describe como actualidad es la constitución del consumo en cultura, con pérdida de vinculación de las identidades con la producción, con las masas como metarrelatos (pág. 189). Con sus conflictos y sus debates. Tensiones entre la globalización homogeneizada y la globalización de la heterogeneidad, la hibridación y la creolización. Tensión que parece tener su superación dialéctica en lo que, siguiendo a Sen, nuestro autor denomina monoculturismo plural.

Especialmente grato y atractivo me ha sido encontrar aplicando su multifacético saber y potencial teórico en la práctica turística. Como casi siempre, el primer paso es enmarcar el comportamiento turístico en los procesos de nuestra civilización. El segundo, el fordismo como marca más concreto para entender cómo hemos entendido el turismo hasta hoy: el 
turismo como un bien más en la cesta de compras, sin nada que ver con las aventureras evocaciones de la burguesía novecentista. De ahí, a cómo el rincón encantador se ha convertido en un no lugar, en directo guiño a Augé. La culpa la tienen los malditos años ochenta (en el consumo, en la organización, en la producción, en el turismo) y un proceso de transformación tecnológico. Pero no todo es tan oscuro, pues en este marco emergen, en el turismo y el consumo en general, grupos aún minoritarios que introducen el discurso mediambientalista en sus prácticas. En directa conexión con esto, el epílogo es una propuesta de recuperación de los sujetos y los actores sociales, rompiendo con el dominio postmoderno que tiró al sujeto por la ventana de los omnipotentes códigos. Son sujetos en prácticas.

Con este libro, Luis Enrique Alonso abre de par en par un enfoque sociológi- co, que como el propio texto refleja ya había sido apuntalado por grandes nombres -desde Halbwachs hasta Bourdieu$y$, sobre todo, con un gran potencial explicativo de los comportamientos concretos de sujetos concretos en contextos concretos. Un enfoque que, tomando en la comparación la propuesta de estudio de las organizaciones referida en su prefacio, contrasta con esas parrilladas de flechas y cuadros abstractos de las pretendidamente sistémicas sociologías de la organización, que se muestran más vacías que nunca. A lo peor, es que nunca pretendieron explicar sino sólo imponerse. Aquí, nuestro autor tal vez no pretenda otra cosa que eso, explicarnos lo que pasa. Para ello, nos vuelve a regalar con su gran capacidad de integración de un pensamiento que, siendo global en muchos sentidos, es particularmente suyo.

Javier Callejo 